\title{
The Future of Environmental Social Work: Looking to Community Initiatives for Models of Prevention
}

\author{
Samantha Teixeira \\ Boston College \\ John Mathias \\ Florida State University \\ Amy Krings \\ Loyola University Chicago, akrings@luc.edu
}

Follow this and additional works at: https://ecommons.luc.edu/socialwork_facpubs

Part of the Social Work Commons

\section{Author Manuscript}

This is a pre-publication author manuscript of the final, published article.

\section{Recommended Citation}

Teixeira, Samantha; Mathias, John; and Krings, Amy. The Future of Environmental Social Work: Looking to Community Initiatives for Models of Prevention. Journal of Community Practice, 27, 3-4: 414-429, 2019. Retrieved from Loyola eCommons, Social Work: School of Social Work Faculty Publications and Other Works, http://dx.doi.org/10.1080/10705422.2019.1648350

This Article is brought to you for free and open access by the Faculty Publications and Other Works by Department at Loyola eCommons. It has been accepted for inclusion in Social Work: School of Social Work Faculty Publications and Other Works by an authorized administrator of Loyola eCommons. For more information, please contact ecommons@luc.edu. c) $(\$) \ominus$

This work is licensed under a Creative Commons Attribution-Noncommercial-No Derivative Works 3.0 License. (c) Taylor and Francis, 2019. 


\title{
The future of environmental social work: looking to community initiatives for models of prevention
}

Samantha Teixeira ${ }^{a}$, John Mathias ${ }^{b}$, and Amy Krings ${ }^{c}$

aSchool of Social Work, Boston College, Chestnut Hill, MA, USA;

${ }^{b}$ College of Social Work, Florida State University, Tallahassee, USA;

'School of Social Work, Loyola University of Chicago, Chicago, IL, USA

\section{Corresponding Author}

Samantha Teixeira, samantha.teixeira@bc.edu, Boston College School of Social Work, 140 Commonwealth Avenue, Chestnut Hill, MA 02467

\section{Copyright Agreement}

The Version of Record of this manuscript has been published and is available in the Journal of Community Practice, 2019, DOI: 10.1080/10705422.2019.1648350

\section{Complete Citation}

Samantha Teixeira, John Mathias \& Amy Krings (2019): The future of environmental social work: looking to community initiatives for models of prevention, Journal of Community Practice, DOI: 10.1080/10705422.2019.1648350

\begin{abstract}
Social work responses to environmental degradation have sought to mitigate harm that has already occurred and create strategies to respond or adapt to environmental hazards. Despite a good deal of literature suggesting the promise of prevention-focused models, social workers have less frequently considered prevention models to address environmental issues. In this manuscript, we consider how communities engaged in environmentally-based prevention work might inform the development of ecosocial work practice. We describe how a prevention-focused agenda, in partnership with communities, can be a promising avenue for ecosocial work practice to address the root causes of environmental degradation and its social impacts.
\end{abstract}

KEYWORDS: Citizen leadership; community practice; environmental justice; sustainable communities; prevention; community 


\section{The future of environmental social work: looking to community initiatives for models of prevention}

Samantha Teixeira, John Mathias, and Amy Krings

Social workers have proposed a number of avenues through which to contribute to addressing the root causes as well as the social and ecological effects of environmental degradation (Ramsay \& Boddy, 2017). The majority of social work responses to environmental degradation and its disparate social impacts have sought to mitigate harm that has already occurred and to create strategies to respond or adapt to disasters (Kemp et al., 2015; Ramsay \& Boddy, 2017). Despite a good deal of social work literature that finds that a focus on prevention is an important component of interventions, social workers have less frequently considered prevention-based practice as a model to address environmental issues. A recent literature review on the state of scholarship in environmental social work identified a strong literature base relating to responses to natural disasters, but limited research on "interventions that can mitigate or prevent crises, such as macro-level sustainable development and conservation" (Krings, Victor, Mathias, \& Perron, 2018, p. 12). In this manuscript, we consider how communities engaged in environmentally-based prevention work might inform the development of ecosocial work practice.

Ecosocial work attends to social and structural inequalities and emphasizes the linkages between social work and ecological issues (Matthies, Närhi, \& Ward, 2001). Scholars of ecosocial work stress the importance of privileging voices outside of the dominant, Western perspective and voices of those who are not traditionally considered to be experts to address social and environmental inequalities. Ecosocial work is rooted in viewing social problems with an ecological lens and promotes addressing environmental and social issues holistically (Matthies et al., 2001). It provides a useful backdrop for contextualizing renewed scholarly interest in environmental social work.

The resurgence in interest in environmental social work is still nascent (Gray, Coates, \& Hetherington, 2013; Ramsay \& Boddy, 2017). Ramsay and Boddy (2017) note that, "The mandate to be environmentally pro-active may be clear, yet application of environmental social work in practice is limited" (p. 69). In fact, much of social work, by design, is reactive. Typical

clinical social work interventions are designed to, for example, react to reports of abuse or treat diagnosed mental health issues. At the community level, social work advocates often mobilize in reaction to threats or in response to existing social and structural issues. Resource constraints often preclude adding a proactive strategy to the standard reactive approach. In environmental social work, some have posited that the lack of a proactive approach may also be due to 
disciplinary norms and boundaries that relegate preventative environmental work to the natural sciences, while making reactive work the domain of the social sciences (Krings et al., 2018).

Yet the need for a preventative social responses to the inequitable impacts of environmental crises such as industrial pollution, deforestation, fresh water scarcity, and climate change could not be more apparent. If prevention guards against the crises of the future, it is nonetheless motivated by the "urgency of now." To that end, we consider the ways in which social workers can act today with "conscientious foresight" to mitigate or prevent future environmental injustices, with a focus on community-based prevention efforts (Alston, 2015). We begin by providing background on the concept of prevention and its application to solving complex social problems, as well as two current initiatives that provide useful jumping off points from which to explore prevention-focused community practice. We then present three brief case examples that illustrate community practice approaches to prevention in ecosocial work. Finally, we discuss key takeaways from the approaches and conclude with implications for community practice.

\section{Background}

Early scholarly discussions of the promise of prevention-focused interventions for social work described it as "early discovery, control, and elimination of conditions which potentially could hamper social functioning" (Rapoport, 1961). A prevention focus affirms core social work values; prevention models are woven into the history of social work, from the Settlement House movement to adolescent problem behavior prevention (Rishel, 2015). This natural fit has led to a robust prevention-focused body of research and practice in some arenas of social work, like adolescent development (see for example, Hawkins, 2006).

A prevention focus is also common in community-centered health promotion aimed at chronic conditions like obesity, and health damaging behaviors like substance use (Wandersman \& Florin, 2003). Likewise, prevention science frameworks focus on going from epidemiology, that is, studies of the prevalence and predictors of problems, to testing preventive interventions and diffusing findings (Hawkins, 2006). While we do not want to overemphasize a medical approach, these concepts may be valuable to community practitioners and inform a more holistic view in line with the ecosocial work focus on the interplay between the social environment, the natural environment and well-being (Närhi \& Matthies, 2018). The Communities that Care Model, which illustrates prevention science in a social work context, helps community coalitions identify prevention needs specific to youth and implement locally-relevant community-based prevention strategies (Hawkins, Shapiro, \& Fagan, 2010). These models may provide lessons for ecosocial work. 
Although not directly focused on prevention, two influential proposals for addressing environmental change bear discussion. One, within social work, aims to address the social response to the human impacts of environmental change through the Grand Challenges for Social Work initiative. The other is the UN Sustainable Development Goals (SDGs) adopted in 2015 by global leaders in an effort to end poverty, protect the planet from degradation, and form global partnerships to ensure peace and prosperity (United Nations General Assembly, 2015).

The Grand Challenges for Social Work encourage social workers and allied disciplines to address pressing social problems through partnerships, innovation, and scientific inquiry. A policy brief written by the group tasked with the Grand Challenge of "creating social responses to a changing environment" highlights the unique position of social workers as potential change-makers and innovators "at the human-environment nexus" (Kemp, Reyes Mason, Palinkas, Rechkemmer, \& Teixeira, 2016, p. 1).

The working paper outlining the agenda for this Grand Challenge focuses on policies and practices in three areas: mitigation, adaptation, and treatment. According to Kemp et al. (2015), these concepts stem from the public health prevention model which includes primary, secondary, and tertiary prevention. Mitigation, or primary prevention, aims to stop environmental changes and limit the degree of change. Adaptation or secondary prevention is focused on addressing the consequences of existing hazards and preventing further consequences in areas of known risk. Treatment, or tertiary prevention, works to alleviate and treat the consequences of problems after they occur (Kemp et al., 2015).

The preventative approaches outlined in the Grand Challenges working paper (Kemp, et al. 2015) and associated policy brief primarily focus on the individual level (e.g., trauma response to prepare for intervention after natural disasters) and the structural level (e.g., advocating for policies and allocating resources to promote equity). The suggestions at the community practice level (e.g., community organizing) are largely reactive. Thus, the community-based prevention approaches we discuss here could fill in gaps in these recommendations.

The UN Sustainable Development Goals (SDGs) focus on ending poverty, protecting the planet, and ensuring prosperity. The SDGs embed relevant ecosocial work themes, connecting economic, social, and ecological aspects of sustainability (Närhi \& Matthies, 2018). For example, SDG Goal 13 warns that climate change and associated natural disasters are occurring and that irreparable damage has already been done, while putting forward a mandate to prevent further harm. These multi-level, preventative measures provide opportunities for social workers to take a lead in establishing scalable interventions that incorporate the multiple actors (e.g., government, private sector, community) necessary to address climate change. 
Drawing on these frameworks, and highlighting the role of community-level practice, we discuss how a prevention-focused, proactive agenda for ecosocial work will provide a role for social workers in collaborative partnerships, and allow us to learn from grassroots groups that have been working to prevent environmental change and its social impacts.

\section{Method}

To better understand how communities engaged in environmentally-based prevention work might inform the development of ecosocial work practice, we employed an instrumental case study method. We present three instrumental case studies that aim to describe the phenomenon of community engaged environmental prevention in the real life context in which it occurs (Baxter \& Jack, 2008). Instrumental case studies are used when the goal of inquiry is to provide insight into an issue and/or help refine a theory (Baxter \& Jack, 2008; Stake, 1995). In instrumental case studies, a case is examined in depth; the goal is not to generalize or compare it to others but to illuminate one case and come to know it in detail (Stake, 1995).

The authors drew on their collective experience and expertise in environmental justice-focused scholarship to select instrumental cases. These cases were selected because of their utility for illustrating and better understanding how community groups undertake environmental prevention work. The first (Approach 1) presents a historical account of a classic environmental justice case. The authors reviewed each instrumental case and interrogated them for lessons specific to understanding how communities can inform the development of ecosocial work practice. Our second case (Approach 2) introduces the Flint Water Study (http://flintwaterstudy.org/about-page/about-us/) as an illustration of how citizen science can prevent environmental health impacts. It draws on data collected through interviews with civic leaders as well as archives of newspaper articles that describe the Flint Water Crisis (see Krings, Kornberg, \& Lane, 2018) for a detailed methodological description). Our third case (Approach 3) describes how community organizers in Kerala, India imagine and put into practice alternative practices with the aim of supplanting the systems that produce environmental injustices. The case is based on two years of ethnographic fieldwork including participant observation and interviews in the local language of Malayalam (see Mathias, 2017 for a detailed description of methods and limitations).

Because these three cases draw on different empirical materials, we have opted to present each individually. Across all three, we briefly describe and contextualize the case before analyzing it as an approach to prevention. In the discussion and conclusion, we compare these approaches and offer an analysis of prevention as a paradigm for community practice. There are several notable limitations to this method of analysis and presentation. First, we intend these cases to be illustrative and generative of creative thought. While we situate them in relation to 
broader literatures and social patterns, we do not attempt to determine generalizability. Second, these cases should be viewed in light of the authors' positionality. While we each have unique identities, we all are faculty at schools of social work in the United States which is the main lens through which we interpreted the cases.

\section{Community approaches to prevention}

\section{Approach 1: community practice shaping policy in Warren County, North Carolina}

Places inhabited by poor people of color are not protected from environmental harm to the same degree as places inhabited by predominantly white and more affluent people (Mohai, Pellow, \& Roberts, 2009). As a result, environmental justice campaigns have emerged to address the practices, policies, and conditions that shape disparities including; unequal enforcement, disparate exposure to harm, and discriminatory and exclusionary practices (Bullard \& Johnson, 2000, p. 557-558). A brief historical example is instructive in our discussion of how community practice skills can be engaged to not only mitigate and adapt to environmental degradation (and root causes of degradation such as racism), but also to further community-based prevention. ${ }^{1}$

In 1978, employees of the Ward Transformer Company traveled rural roads across North Carolina, secretly dumping a chemical mixture containing polychlorinated biphenyl (PCB) to avoid paying to properly dispose of it (McGurty, 1997). Because this dumping occurred along state roads, North Carolina was responsible for remediating the contamination (McGurty, 1997). The state identified a farm in Warren County, a rural county populated predominantly by poor, black residents, on which to dispose of the PCB-contaminated soil. Residents resisted vigorously, but after three years of unsuccessfully trying to block the site through the courts, permits were granted for the Warren County dump site (McGurty, 1997).

At this stage, Warren County resident advocates reframed the movement with the support of prominent civil rights leaders. McGurty (2000) notes that the initial strategy, used for the first years of the resistance between 1978 and 1979, was to frame the argument against the dumpsite using a "Not in My Backyard" argument, citing threats to local economic development and stigma associated with hosting a toxic waste site. Seeing that the initial strategy was failing, in 1982, the Warren County Citizens Concerned about PCB shifted to frame the dumpsite as an example of environmental racism which attracted substantial support from the civil rights movement, sparked direct action, and connected their experience of disparate environmental harm directly to racism and political powerlessness among the poor (McGurty, 2000, p. 376). The Warren County Citizens Concerned about PCB, who led the initial legal battles, were comprised largely of white landowners without direct action experience. When they joined 
forces with a local black Baptist church affiliated with the United Church of Christ (UCC), they gained support from powerful black leaders with experience in community organizing.

The reframing and coalition with the UCC marked a transition to a more disruptive community organizing strategy. In late 1982, mirroring the civil rights march at Selma, organizers staged a 60 mile march from Warren County to the state capital and EPA offices in Raleigh (McGurty, 1997). Protesters intervened, lying down and blocking the roads as trucks came to dump the PCB-contaminated soil. These direct actions drew national attention and, despite failing to protect Warren County residents, shifted the movement's aims and eventual impacts from local resistance to national policy change.

The aftermath of Warren County protests included further organizing efforts, a surge of academic research, and federal legislative action (Agyeman, Schlosberg, Craven, \& Matthews, 2016). The protests led members of Congress to request an analysis at the national level of the relationship between hazardous waste dump site locations and the demographics of area communities, published in 1983 (Agyeman et al., 2016). It also prompted a report, "Toxic Wastes and Race in the United States" (1987) which set the stage for the development of the fundamental principles of environmental justice created at the First National People of Color Environmental Leadership Summit. These reports, along with the attention at the government level, initiated academic research to empirically test environmental racism in facility siting, which continues to be a robust area of work today. Perhaps most importantly, Environmental Justice Executive Order 12250 was signed in February 1994, mandating that the mission of every federal agency include environmental justice.

This example provides a sense of how, historically, the environmental justice movement was shaped by community practice and how a community went from a reactive local agenda to stop an undesirable land use to a national policy that aims to prevent harm caused by environmental racism. Bullard, Mohai, Saha, and Wright (2008) note that the local struggles "blossomed into a multi-issue, multi-ethnic, and multi-regional movement" (p. 376). The history of the environmental justice movement shows how integral community residents have been in sparking policies aimed at preventing environmental harm.

\section{Approach 2: street science and the Flint Water Crisis}

To prevent environmental injustices, there is a need for social workers to advocate for proactive environmental regulations, monitoring, and enforcement. In a political climate where environmental regulations are being reduced or eliminated (consider the US departure from the Paris Climate Accords), when a community is contaminated, the burden of proof is often pushed to those who are harmed. This presents an important intervention point for ecosocial workers. By 
partnering with communities to rigorously document impacts, local concerns can be leveraged to gain the attention of media and enforcement agencies. The importance of this sort of partnership, known as "street science" (Corburn, 2005), can be demonstrated through an examination of the Flint water crisis.

Decades of divestment in Flint, Michigan were caused by a combination of economic and political forces including closure of auto plants, a decline in urban investment by the federal government, and racial segregation (Highsmith, 2009). Consequently, when the City was faced with bankruptcy, the Michigan Governor appointed a receiver (known as an emergency manager) whose job was to balance the city's budget without raising taxes, securing funding from state or national government, or negotiating with creditors. This context created an environment in which city services were eliminated or reduced. Decisions were made to provide and monitor the quality of Flint's drinking water in the least expensive manner possible.

Soon after the City shifted its water source to the local Flint River, residents began to notice health impacts including skin rashes, burning eyes, and hair falling out. Representatives from the State Department of Environmental Quality responded that these problems were exaggerated, and any problems with the drinking water were short-term. Despite assurances, residents reported that their health problems were growing worse and some even died from Legionnaire's disease. Later, it was discovered that Flint residents had been exposed to lead due to deteriorating water pipes.

The Flint water crisis reveals multiple points in which decisions that were made in the name of fiscal austerity resulted in public health crises. Yet, to a degree, residents and grassroots community organizations were able to prevent a crisis that could have been even larger in scope if not for local pressure to change the water source (Krings et al., 2018). These groups used many tactics familiar to community practitioners. They asked questions and pressured officials in public meetings, organized protests, pursued a class action lawsuit, educated neighbors, and distributed bottled water and filters. Additionally, they sought out and partnered with scientists who were able to validate local claims in a way that was viewed to be "credible" by external groups including funders and media. The Flint Water Study, for example, was a partnership between researchers at Virginia Tech and a grassroots coalition of residents and community organizations (http://flintwaterstudy. org/about-page/about-us/). The group collected and analyzed its own water samples, discovering that the water was, indeed, not safe to drink. Further, the Study suggested the City had been cutting corners, with the knowledge of the State Department of Environmental Quality, to test the water in the least rigorous way possible. While the Flint Water Study alone did not lead the City of Flint to switch back to the safer and more expensive water provided through the City of Detroit, pressure from the media and foundations, who were more inclined to believe the Study's report than residents' complaints, ultimately did. 
The street science approach, and the Flint case in particular, shed light on ways that community practitioners can support the advancement of environmental justice. Not all residents of marginalized communities can access researchers and therefore it is likely that many communities that would benefit from such partnerships will fall through the cracks. Similarly, there is a danger that researchers will only partner with community groups in response to visible health impacts as opposed to slow-onset disasters that are less visible. This reactive approach has been common within environmental social work interventions (Krings et al., 2018; Mason, Shires, Arwood, \& Borst, 2017). Community practitioners are thus positioned to extend the use and efficacy of street science by assisting civic groups in locating and developing on-going relationships with academic partners. Furthermore, community practitioners are needed to develop inclusive decision-making processes that attend to power imbalances between residents and researchers. Finally, community practitioners can recruit, train, and support residents who might not otherwise have the skills or confidence to engage in street science.

Additionally, the Flint case reveals opportunities for community practitioners to increase the political power of residents and communities - goals that are central to the mission and ethics of the social work profession. Examining the role (and lack thereof) of national media in the Flint Water Crisis, Jackson (2017) notes that reporters did not "credential" residents, that is, they did not give credence to their complaints and instead focused on the voices of Flint leaders who defended and justified the shift in the city's water source. Jackson argues that if reporters had deemed residents to be credible before researchers stepped in, then the crisis could have been curtailed. Thus, beyond partnering with local groups, ecosocial community practitioners and scholars can work with communities to counter classist and racial bias embedded in conceptions of expertise and authority. This includes the development of institutions that are accountable to residents, providing information in a transparent and timely way, and including public participation in the design and implementation of environmental policy.

\section{Approach 3: experiments with alternatives in Kerala, India and Detroit, USA}

Environmental injustices are not only caused by inequitable policies and hierarchies of expertise; they are also deeply rooted in ordinary social practices like shopping, eating, or inhabiting. As such, those pursuing environmental justice have sought to develop alternative practices that transform humans' relations to nature and to one another. For example, for environmental activists in Kerala, India imagining and experimenting with "alternatives" (badal) is crucial to the pursuit of environmental justice and can inform ecosocial work practice.

As the second author of this manuscript found during ethnographic research on environmental justice organizing in Kerala (Mathias, 2017), the logic of such alternatives can be vividly seen in activists' efforts to develop and promote new methods of organic farming. In 
visiting the experimental farm of a farmer/ activist named Peter, for example, Mathias (2017) noticed how different it looked from other farms he had seen in either India or the US. Rather than even rows of crops in an open field, this farm was more like a meadow of pumpkin and other vegetables, growing amidst banana and jackfruit trees, with plenty of weeds mixed in as well. Peter explained that his approach to farming is to let the weeds grow and avoid putting too much work into tending the plants. Instead, he said, he just planted things, let them grow, and picked whatever came.

Peter's non-intensive approach to farming was not born of laziness. Rather, he was frugal with his time because he hoped to show others that organic farming can be a practical, profitable activity. For several decades, agrarian livelihoods have become increasingly precarious in India, with farmers often trapped in downward spirals of debts for seed, pesticide, and fertilizer (Deshpande \& Nagesh, 2005; Mohanty, 2005; Walker, 2008). Food security has become a major concern, particularly in urbanizing regions like Kerala (Kannan, 2000; Kumar, 2017). Peter and others like him see organic farming as the cornerstone of a more just social order - a mechanism for liberating India's lower classes from exploitative economic structures. Thus, alternative agriculture is as much about community organizing as farming. Though it often begins with experiments on activists' own land, it is only successful insofar as it is taken up by a community. To that end, Peter holds educational programs for teenagers who live nearby and talks with his neighbors about the income he is making from his farming. The real fruits of his labor are not the vegetables in his own garden, but the cultural and socio-economic changes he hopes alternative approaches to farming will bring for his community. Aside from organic farming, Indian activists are developing other alternatives such as building homes out of earth instead of concrete, selling cloth alternatives to the plastic shopping bag, or drinking an herbal preparation called jappi instead of coffee or tea. Though these practices vary with regard to both the means and desired ends of social change, the logic of such alternatives as an approach to prevention can be roughly compared with the notion of "alternative energy." Just as alternative energy attempts to prevent climate change by supplanting the carbon dioxide-producing fossil fuels that contribute to it, so earth homes supplant mining industries that chew up forests and poison rivers, and herbs supplant tea leaves grown on exploitative plantations.

Globally, a wide range of initiatives share a similar logic of developing alternatives to prevent future environmental injustices. Närhi and Matthies (2018) describe a range of "ecosocial transition" projects such as communal housing, through which "local communities develop new kinds of living models that aim at self-sufficiency and social justice" (p. 496). Similarly, Loh and Agyeman (2017) describe how "solidarity economy" movements are using participatory budgeting, land trusts, and other alternative practices that make "serving people and ecological sustainability ... the goal of economic activity, rather than maximization of profits ( $p$. 261, quoting Quinones 2008, 13). White's (2011) study of women farmers in the Detroit Black Community Food Security Network (DBCFSN) offers an example that parallels the alternative 
agriculture practices of activists in Kerala. For these women, White (2011) argues, urban farming differs from protests because it is not a reaction to environmental destruction but a proactive assertion of control over the food supply and, more generally, over their relation to the earth. Such initiatives vary widely in how they theorize the problems to which they are developing alternatives. However, they share an appreciation for how environmental injustices are entangled with economic systems as well as a belief that systemic change can be achieved by re-inventing everyday social practices.

The latter notion - that neighborhood groups, for example, can produce more just economic systems - raises one of the chief challenges for the pursuit of environmental justice alternatives. Often, environmental justice movements have been approached as locally bounded, to specific geographic sites of pollution (Mathias, 2017). Even if it is easy to see the roots of such problems in geographically-dispersed social systems, it can be difficult to imagine how localized organizations can challenge these systems. Perhaps one reason that urban gardening seems a particularly promising alternative is that it shows how global food systems can, within a limited domain, be supplanted by a small number of people and an empty lot. But other environmental justice problems, like climate change, appear less amenable to local alternatives.

Such challenges of scale point to the need for creativity in this approach to preventing environmental injustice. Social workers can be a resource for such creative thinking. For example, they can mediate knowledge sharing between, for example, activist farmers in the US and India. Cross-national and cross-cultural knowledge sharing will be vital to developing alternatives because encounters with difference stimulate the imagination of new possibilities. Thus, by facilitating knowledge sharing, social workers can help develop new social systems that promote environmental justice.

\section{Discussion}

Ecosocial workers need to engage at the community level, with a prevention focus, to effectively promote social and environmental justice. Yet, social workers tend to be reactive when addressing environmental issues (Krings et al., 2018). Thus, this manuscript aims to articulate opportunities for ecosocial workers, in partnership with community and grassroots groups, to prevent environmental change and its social impacts. The three approaches demonstrate how prevention-focused work has been enacted by communities over time and across the globe to prevent environmental degradation and its root causes.

While policy advocacy, street science, and community development alternatives can all contribute to preventing environmental injustice, they do so in different ways. Organizing in Warren County was initially aimed at preventing toxic waste from being dumped on a specific 
site. However, the policy advocacy inspired by this organizing was aimed further upstream, at preventing the racist siting of toxic industries from happening again.

In the context of inadequate policy and chronic failures of enforcement, the Flint Water Study took a different tack. Residents sought out and partnered with researchers to examine the quality of Flint's drinking water. These findings were able to prevent the spread of a public health crisis by convincing external allies, such as media and foundations, to pressure regulators and elected officials to change the City's water supply. This approach mixed immediate downstream interventions, such as providing bottled water to residents, with long-term upstream strategies aimed to address the root causes of the crisis (Braveman, Egerter, \& Williams, 2011). Like street science, urban gardening can increase community control; these kinds of alternatives aim at the roots of environmental injustice, attempting to prevent inequities by supplanting the systems that produce these inequities.

Kemp et al. (2015) conceptualize mitigation, adaptation, and treatment (or primary, secondary, and tertiary levels of prevention), as potentially useful organizing heuristics rather than immutable categories. Considering primary, secondary, and tertiary levels of prevention can be useful for analyzing and planning community-based approaches to preventing environmental injustice. Both policy advocacy and developing alternative social systems might be considered primary in the public health idiom as both intervene to prevent harm from happening at all. However, at least some alternatives might be considered more primary insofar as they seek to root out injustices prior to state oversight and regulation. Street science, by contrast, can be likened to secondary or tertiary levels of prevention, aiming to affect those known to be at elevated risk for harm and to mitigate harm that has already occurred. While we have contrasted such approaches with more "reactive" work like providing resources and mental health treatment in the aftermath of natural disasters, the latter might also be thought of as tertiary prevention to the extent that they attempt to ameliorate the long-term impacts of harm for those at highest risk.

These distinctions of degree can help to clarify what we mean by prevention, but it should be noted that aims of community interventions are often multiple. For example, Flint residents' use of street science has been the basis for calls to ameliorate the long-term impacts of lead poisoning as well as calls for stronger regulation. In practice, these different aims and activities will often co-occur. Holding them apart analytically is useful, however, when it facilitates strategic thinking and shows the many roles community practitioners can play.

Across each of the case approaches, and in the existing literature, the challenge of scale is a cross-cutting theme. Issues of environmental degradation are daunting challenges because they typically begin with powerful actors or forces seemingly well-beyond the control of community-based groups, which exert their effects from afar (Freudenberg, 2004).

Prevention-focused work requires us to think creatively about how communities, and community 
practitioners in a supporting role, can work across different scales to identify points of disruption in the root causes of environmental change (Ramsay \& Boddy, 2017). Though organizing in Warren County and Flint did not immediately succeed in preventing harm locally, each incrementally advanced prevention objectives and raised awareness of environmental injustices, eventually leading to work that may prevent such harms in the future.

Limits of time and resources also pose practical challenges for preventative approaches. Reactive interventions like the Warren County protests tend to be the norm in environmental movements because acute situations require immediate solutions. As in much of social work practice, reactive solutions tend to get the lion's share of resources while proactive solutions take so much time and effort to develop that individuals and communities simply might not have capacity for both. However, balancing reactive and preventative work need not be a zero-sum game. Community practitioners may find ways to integrate prevention by looking for points where responses to current crises can catalyze action for enacting new policy, bolstering community control, or creating partnerships that can more effectively guard against future injustices.

Despite these challenges, we see great promise in the community initiatives described here as models for prevention in community practice and ecosocial work. A combination of macro social work practices like learning from partner organizations, coalition building, and policy advocacy, combined with the lessons learned from community initiatives will be necessary to mitigate and prevent future harm from large-scale environmental problems.

\section{Conclusion}

An orientation toward prevention in ecosocial work means that "social workers are viewed as political actors working toward social change rather than adjusting to current conditions of society" (Närhi \& Matthies, 2018, p. 32). We acknowledge that much environmentally-focused community practice work, particularly in the environmental justice arena, has been carried out by community leaders and groups outside of social work. Nonetheless, social work practitioners have skill-sets that make us uniquely situated to support these practitioners and begin setting the stage for preventing future harm from environmental issues (Teixeira \& Krings, 2015). Social work scholars can support community groups and practitioners in advancing environmental justice by approaching environmental degradation with an eye toward being proactive. In practice, this means partnering with local groups and pressing for change in the root causes of environmental problems, fighting for racial and income equity, developing institutions that are accountable to marginalized communities, and improving public 
participation in the design of environmental policy. It also requires thinking creatively about how communities can work across different scales and where the points of disruption may lie.

We present a case for approaching prevention as an essential part of community practice for ecosocial work. Though there are challenges inherent in such an approach, community practice already includes many models for preventing environmental degradation and promoting environmental justice. Community practitioners have much to learn from community-based prevention initiatives like those described in this manuscript and, in partnership with community groups and scholars, can address root causes of environmental degradation and build more environmentally just global futures.

\section{Note}

1. It should be noted that the definition of environmental justice has been expanded since these early efforts focused on race and class-based disparities in the United States. Research and practice has since developed to begin to understand the intersectional impacts of environmental injustices incorporating, for example, gender, geographic location, historic and social context (Malin \& Ryder, 2018).

\section{Disclosure statement}

No potential conflict of interest was reported by the authors.

\section{Funding}

This work was supported by the Fulbright Hays Doctoral Dissertation Research Award grant \# P022A120002-002.

\section{References}

Agyeman, J., Schlosberg, D., Craven, L., \& Matthews, C. (2016). Trends and directions in environmental justice: From inequity to everyday life, community, and just sustainabilities. Annual Review of Environment and Resources, 41, 321-340. doi:10.1146/annurev-environ -110615-090052

Alston, M. (2015). Social work, climate change and global cooperation. International Social Work, 58(3), 355-363. doi:10.1177/0020872814556824

Baxter, P., \& Jack, S. (2008). Qualitative case study methodology: Study design and implementation for novice researchers. The Qualitative Report, 13(4), 544-559.

Braveman, P., Egerter, S., \& Williams, D. R. (2011). The social determinants of health: Coming of age. Annual Review of Public Health, 32, 381-398. doi:10.1146/annurevpublhealth-031210-101218 
Bullard, R. D., \& Johnson, G. S. (2000). Environmentalism and public policy: Environmental justice: Grassroots activism and its impact on public policy decision making. Journal of Social Issues, 56(3), 555-578. doi:10.1111/0022-4537.00184

Bullard, R. D., Mohai, P., Saha, R., \& Wright, B. (2008). Toxic wastes and race at twenty: Why race still matters after all of these years. Environmental Law, 38, 371-411.

Corburn, J. (2005). Street science: Community knowledge and environmental health justice. Cambridge, MA: MIT Press.

Deshpande, R. S., \& Nagesh, P. (2005). Farmers' distress: Proof beyond question. Economic and Political Weekly, 40(44/45), 4663-4665.

Freudenberg, N. (2004). Community capacity for environmental health promotion: Determinants and implications for practice. Health Education \& Behavior, 31(4), 472-490.

doi:10.1177/1090198104265599

Gray, M., Coates, J., \& Hetherington, T. (Eds.). (2013). Environmental social work. New York, NY: Routledge.

Hawkins, J. D. (2006). Science, social work, prevention: Finding the intersections. Social Work Research, 30(3), 137-152. doi:10.1093/swr/30.3.137

Hawkins, J. D., Shapiro, V. B., \& Fagan, A. A. (2010). Disseminating effective community prevention practices: Opportunities for social work education. Research on Social Work Practice, 20(5), 518-527. doi:10.1177/1049731509359919

Highsmith, A. R. (2009). Demolition means progress: Urban renewal, local politics, and state sanctioned ghetto formation in Flint, Michigan. Journal of Urban History, 35(3), 348-368. doi:10.1177/0096144208330403

Jackson, D. Z. (2017) Environmental justice? Unjust coverage of the Flint water crisis. Shorenstein center on media, politics and public policy. Retrieved from https://shorenstein center.org/wp-content/uploads/2017/07/Flint-Water-Crisis-Derrick-Z-Jackson-1.pdf

Kannan, K. P. (2000). Food security in a regional perspective: A view from 'food deficit' Kerala (CDS Working Paper 304). Thiruvananthapuram, India: Centre for Development Studies.

Kemp, S. P., Palinkas, L. A., Wong, M., Wagner, K., Reyes Mason, L., Chi, I., ... Rechkemmer, A. (2015). Strengthening the social response to the human impacts of environmental change. Cleveland, OH: American Academy of Social Work and Social Welfare. Retrieved from http:/grandchallengesforsocialwork.org/grand-challenges-initiative/12challenges/create-social-responses-to-a-changing-environment/

Kemp, S. P., Reyes Mason, L., Palinkas, L. A., Rechkemmer, A., \& Teixeira, S. (2016, September). Policy recommendations for meeting the grand challenge to create social responses to a changing environment (Policy Brief No. 7). Cleveland, OH: American Academy of Social Work and Social Welfare. Retrieved from: https://openscholarship. wustl.edu/cgi/viewcontent.cgi? article $=1787 \&$ context $=$ csd_research 
Krings, A., Kornberg, D., \& Lane, E. (2018). Organizing under austerity: How residents' concerns became the Flint water crisis. Critical Sociology, 45(4-5), 583-597. doi:10.1177/0896920518757053

Krings, A., Victor, B. G., Mathias, J., \& Perron, B. E. (2018). Environmental social work in the disciplinary literature, 1991-2015. International Social Work, 002087281878839. doi:10.1177/0020872818788397

Kumar, P. (2017). Food and nutrition security in India: The way forward. Agricultural Economics Research Review, 30(1), 1-21. doi:10.5958/0974-0279.2017.00001.5

Loh, P., \& Agyeman, J. (2017). Boston's emerging food solidarity economy. In A. Alkon \& J. Guthman (Eds.), The new food activism: Opposition, cooperation, and collective action (pp. 257-283). Berkeley, CA: University of California Press.

Malin, S. A., \& Ryder, S. S. (2018). Developing deeply intersectional environmental justice scholarship. Environmental Sociology, 4(1), 1-7. doi:10.1080/23251042.2018.1446711

Mason, L. R., Shires, M. K., Arwood, C., \& Borst, A. (2017). Social work research and global environmental change. Journal of the Society for Social Work and Research, 8(4), 645-672. doi:10.1086/694789

Mathias, J. (2017). Scales of value: Insiders and outsiders in environmental organizing in South India. Social Service Review, 91(4), 621-651. doi:10.1086/695352

Matthies, A., Närhi, K., \& Ward, D. (2001). Taking the eco-social approach to social work. Reflections on three European countries. In A. Matthies, K. Närhi, \& D. Ward (Eds.), The eco-social approach in social work. (p. 5-15). Jyväskylä, Finland: Sophi. Retrieved from https://jyx.jyu.fi/bitstream/handle/123456789/48562/SoPhi58_978-951-39-6497-9.pdf? sequence $=1$

McGurty, E. M. (1997). From NIMBY to civil rights: The origins of the environmental justice movement. Environmental History, 2(3), 301-323. doi:10.2307/3985352

McGurty, E. M. (2000). Warren County, NC, and the emergence of the environmental justice movement: Unlikely coalitions and shared meanings in local collective action. Society \& Natural Resources, 13(4), 373-387. doi:10.1080/089419200279027

Mohai, P., Pellow, D., \& Roberts, J. T. (2009). Environmental justice. Annual Review of Environment and Resources, 34(1), 405-430. doi:10.1146/annurev-environ-082508-094348

Mohanty, B. B. (2005). 'We are like the living dead': Farmer suicides in Maharashtra, Western India. The Journal of Peasant Studies, 32(2), 243-276. doi:10.1080/03066150500094485

Närhi, K., \& Matthies, A. (2018). The ecosocial approach in social work as a framework for structural social work. International Social Work, 61(4), 490-502. doi:10.1177/0020872816644663

Ramsay, S., \& Boddy, J. (2017). Environmental social work: A concept analysis. The British Journal of Social Work, 47(1), 68-86. 
Rapoport, L. (1961). The concept of prevention in social work. Social Work, 6, 3-12. doi:10.1093/sw/6.1.3

Rishel, C. (2015). Establishing a prevention-focused integrative approach to social work practice. Families in Society: The Journal of Contemporary Social Services, 96, 125-132. doi:10.1606/1044-3894.2015.96.15

Stake, R. E. (1995). The art of case study research. Thousand Oaks, CA: Sage.

Teixeira, S., \& Krings, A. (2015). Sustainable social work: An environmental justice framework for social work education. Social Work Education, 34(5), 513-527. doi:10.1080/ 02615479.2015.1063601

United Nations General Assembly (2015, October 21). Transforming our world: The 2030 agenda for sustainable development. A/RES/70/1. Retrieved from https://sustainabledevelop ment.un.org/post2015/transformingourworld

Walker, K. L. M. (2008). Neoliberalism on the ground in rural India: Predatory growth, agrarian crisis, internal colonization, and the intensification of class struggle. The Journal of Peasant Studies, 35(4), 557-620. doi:10.1080/03066150802681963

Wandersman, A., \& Florin, P. (2003). Community interventions and effective prevention. American Psychologist, 58(6-7), 441. doi:10.1037/0003-066X.58.6-7.441

White, M. (2011). Environmental reviews \& case studies: D-Town farm: African American resistance to food insecurity and the transformation of Detroit. Environmental Practice, 13 (4), 406-417. doi:10.1017/S1466046611000408 